\title{
EVOLUÇÃO DA CADEIA PRODUTIVA AVÍCOLA: UM COMPARATIVO DE 2004 À 2013
}

Marli Aguirre Aranda ${ }^{1}$, Alessandra Canuto da Costa ${ }^{1}$, Rodrigo Garófallo Garcia ${ }^{2}$, Clandio Ruviaro Favarini ${ }^{2}$, Irenilza de Alencar Nääs ${ }^{3}$

1. Mestrandos em Agronegócios da Universidade Federal da Grande Dourados, Dourados, MS, marliedego@hotmail.com

2. Docentes do Programa de Pós-Graduação em Agronegócios da Universidade Federal da Grande Dourados, Dourados, MS

3. Bolsista Nacional Sênior da Universidade Federal da Grande Dourados, Dourados, MS

Recebido em: 08/09/2015 - Aprovado em: 14/11/2015 - Publicado em: 01/12/2015 DOI: http://dx.doi.org/10.18677/Enciclopedia_Biosfera_2015_156

\section{RESUMO}

A evolução da cadeia produtiva avícola no Brasil ocorre desde a década de 50 e, através de investimento tecnológico, avanços nas áreas de nutrição, melhoramento genético, manejo e sanidade animal, a produção brasileira vem ganhando destaque tanto no mercado interno como no externo. Atualmente, o Brasil ocupa o terceiro lugar na produção mundial de carne de frango, é o segundo maior consumidor e o maior exportador do setor. Esse sucesso se deve também pela integração que ocorre entre a granja e a indústria, proporcionando maior padronização e qualidade do produto final. Desta forma, este artigo teve como objetivo analisar a evolução produtiva da cadeia avícola no Brasil no período entre 2004 à 2013. O estudo foi realizado da forma descritivo-exploratória, com abordagem quantitativa. $O$ levantamento de dados foi realizado com base em pesquisa bibliográfica nas bases de informações do setor. Os dados levantados revelam grande aumento na variação da evolução produtiva da cadeia ao longo do período, mantendo-se estável de modo a garantir a competitividade do setor. Entretanto, no último ano houve um pequeno recuo na produção. Para as variáveis de consumo e exportação houve uma significativa ascensão ao longo dos anos estudados.

PALAVRAS-CHAVE: agronegócio, frango de corte, mercado.

\section{EVOLUTION OF PRODUCTION CHAIN POULTRY: A COMPARATIVE 2004 TO 2013}

\footnotetext{
ABSTRACT

The evolution of poultry production chain in Brazil is from the 50 s and through technology investment, advances in nutrition, breeding, management and animal health, Brazilian production has been gaining attention both domestically and externally. Brazil currently ranks third in world production of poultry meat, is the second largest consumer and the largest exporter in the sector. This success is due also for the integration that occurs between the farm and the industry, providing greater standardization and quality of the final product. Thus, this article aimed to ENCICLOPÉDIA BIOSFERA, Centro Científico Conhecer - Goiânia, v.11 n.22; p.1250 
analyze the evolution of poultry production chain in Brazil amongst 2004 and 2013. The study was carried out in descriptive and exploratory way, with a quantitative approach. Data collection was based on a bibliographic research in the industry databases. The data showeda large increase in the variation of the production chain evolution over the period, remaining stable in order to guarantee the sector's competitiveness. However, in the last year there was a slight decrease in the production. For the consumption and the export variables there was a significant rise over the years studied.

KEYWORDS: agribusiness, broiler, market.

\section{INTRODUÇÃO}

A cadeia produtiva da avicultura começou a evoluir no Brasil em 1950, com maior intensidade a partir da década de 60, através de avanços que ocorreram nas áreas de melhoramento genético, nutrição, manejo e sanidade, assim como pela maior inserção de tecnologia no setor e instalações mais adequadas aos animais (ESPINDOLA, 2012). Desta forma, a produção avícola vem se destacando no cenário mundial e, atualmente, o Brasil é o terceiro maior produtor de carne de frango, e o maior exportador mundial do produto (UBABEF, 2014). Esse potencial competitivo alcançado se deve a organização e coordenação da cadeia, além da parceria estratégica entre produtor e indústria, a chamada produção vertical, na qual a empresa oferece os pintainhos, assim como treinamento para auxiliar o produtor no manejo com os animais (TALAMINI, et al., 2013; ZANELLA, et al., 2013).

Do total produzido pelo setor cárneo no país a carne de frango, com um total de $57,0 \%$, é a carne mais produzida, seguida da carne bovina, com $32,1 \%$ do total e, em seguida vem a carne suína com 10,9\% do total (BRADESCO \& DEPEC, 2015). De Acordo com a Associação Brasileira de Proteína Animal-ABPA, (2014), do total produzido pelo setor cárneo em 2014, 12,75 milhões toneladas foram de carne de frango, seguida de 10,23 milhões toneladas da carne bovina e logo em seguida a suína com 3,47 milhões toneladas. Pode-se dizer que é um setor de destaque dentro do país e com alta competitividade internacional, tendo em vista que atualmente em termos de produção mundial fica atrás apenas dos Estados Unidos e da China.

Em 2013, o país produziu cerca de 12 milhões de toneladas de carne de frango, essa produção se dividiu em carne industrializada, salgada, inteira e cortes. Deste total, $32 \%$ foram destinadas ao mercado internacional, cerca de 4 milhões de toneladas (UBABEF, 2014; ABPA, 2014). TALAMINI et al. (2013) afirmam que a exportação de frangos ocupa a segunda posição em importância no agronegócio brasileiro e está na sexta posição nas exportações totais. O relatório de atividades da UBABEF (2014) traz o ranking de exportação por empresas no ano de 2012 e, dentre as primeiras do ranking, tem-se em primeiro lugar a Brf-Brasil Foods S. A. e, em segundo lugar, a JBS (José Batista Sobrinho) Frangosul, entre outras que compõem o topo desta lista. Isso demonstra a grande importância desta cadeia dentro do país e o seu nível de competitividade, quando vista como um sistema agroindustrial.

Diante do contexto exposto, o objetivo do estudo foi o de avaliar a evolução produtiva da carne de frango no Brasil, durante o período de 2004 a 2013, analisando os índices de produção, consumo, exportações e principais destinos da carne de frango produzida no país. 


\section{VISÃO SISTÊMICA DE CADEIA PRODUTIVA}

Em 1957 foi apresentado o primeiro conceito de agronegócios pelos pesquisadores da Universidade de Harvard, John Davis \& Ray Goldberg, que não conseguiam ver a cadeia produtiva de modo isolado, mas sim em conjunto, como um sistema que envolve bem mais do que a produção em si. Eles diziam que o agronegócio envolvia todas as operações ligadas à produção e distribuição de suprimentos agrícolas, ou seja, envolvia as atividades desde o processo de produção (insumos), armazenamento, processamento e distribuição, até chegar ao consumidor final (DAVIS \& GOLDBERG, 1957). Este modo de ver a agricultura, não como um setor isolado, mas como um sistema, é compartilhado por CASTRO (2001) que afirma que o setor de agronegócios é composto por cadeias produtivas que possuem componentes, interligando-a a outros sistemas. Um conjunto de operações que envolvem além da produção, o processamento, armazenamento, distribuição e comercialização dos produtos que foram produzidos no setor agropecuário, até que cheguem ao consumidor final. Deste modo, pode-se dizer que o agronegócio é o sistema maior, que engloba vários outros pequenos sistemas que são interligados entre si.

Neste sentido PIZZOLATTI (2004) afirma que o agronegócio possui agentes que participam da cadeia em cada elo, desde o mercado de insumos e fatores que irão contribuir para a produção, antes da porteira, quanto a produção em si, ou seja, dentro da porteira, até atingir o processamento, transformação, distribuição e comercialização deste produto, que ocorre depois da porteira. Pode-se dizer que o processo produtivo envolve vários agentes antes da produção, durante a produção propriamente dita e, depois da produção, constituindo diferentes subsistemas ao longo da cadeia produtiva. São estes subsistemas que compõem a cadeia produtiva como um conjunto dos componentes que interagem no processo de produção, isso inclui os sistemas produtivos, fornecedores de serviços e insumos, processamento, transformação, distribuição e comercialização, até atingir os consumidores finais (CASTRO, 2001). O objetivo é atender os anseios do consumidor final e, para tanto, conta com outros agentes no decorrer de seus processos.

BATALHA (1995) relata que a cadeia produtiva está inserida entre dois grandes corpos da teoria econômica, sendo eles a análise microeconômica e a macroeconômica, na qual é possível observar a interligação de suas definições de foco que são: o ciclo de operações e transformações ao longo do processo, as relações que o constituem sendo elas comerciais e financeiras e, por fim, as ações econômicas que envolvem as operações em todos os níveis. Para BATALHA \& SILVA (2008) a cadeia de produção envolve as operações de transformação dissociável, que podem ser separadas distintamente e, ao mesmo tempo num campo superior, ser interligadas entre si. Sendo estas as relações comerciais e financeiras que ocorrem antes e a após a produção e as ações econômicas, que garantem a produção e a articulação das operações, a fim de atender as necessidades do consumidor final.

\section{SISTEMAS AGROINDUSTRIAIS}

O conceito de Sistema Agroindustrial (SAG) tem como característica a noção de conjunto, em que os insumos, a produção agropecuária, as indústrias de alimentos e o sistema de distribuição estão correlacionados entre si. Portanto, a análise compartimentada de cada agente não seria possível, devendo ser realizada em conjunto com os agentes para que não ocorra e ou exerçam, de alguma forma, 
influência sobre outros agentes integrantes de determinado SAG (SOUZA \& AVELHAN, 2009).

Segundo BATALHA \& SILVA (2008) os sistemas agroindustriais são caracterizados por um conjunto de relações que envolvem o meio de produção desde antes da porteira, quanto dentro e após a porteira, tendo como principal foco o macrossegmento rural, industrial e de distribuição (Figura 1).

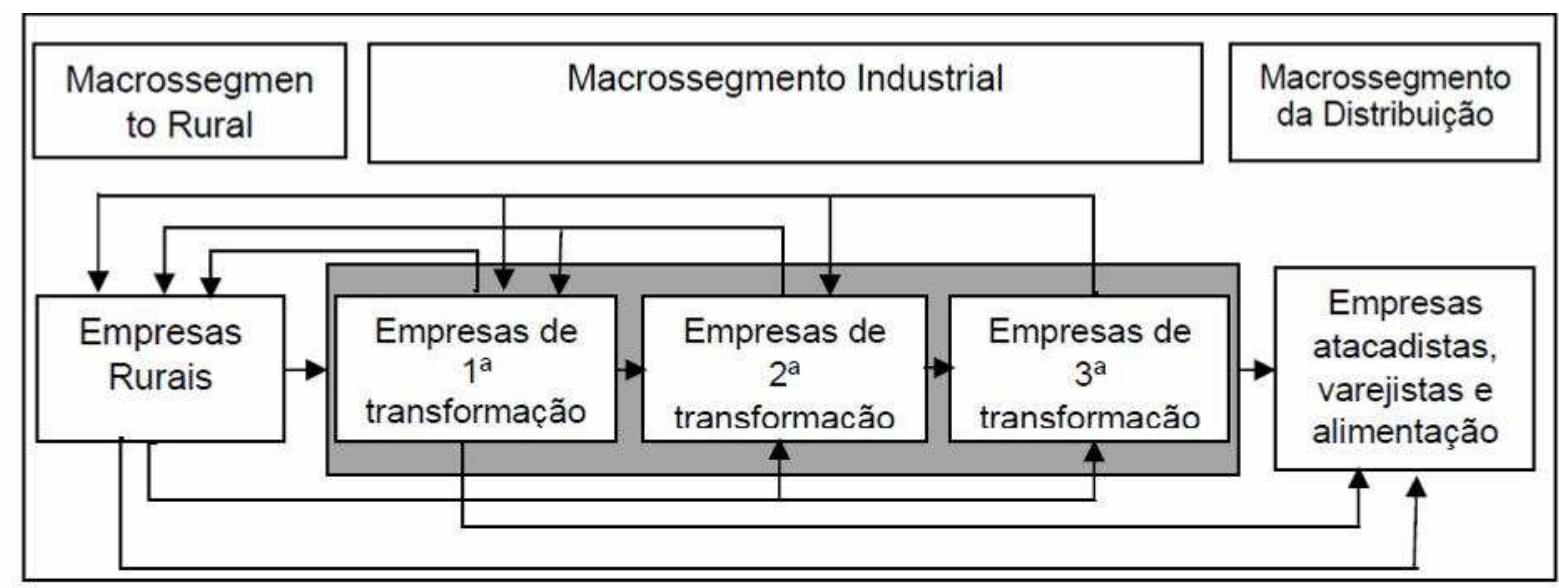

FIGURA 1 - Sistema Agroindustrial - Subsistemas e fluxos de suprimentos. Fonte: BATALHA \& SILVA 2008.

O macrossegmento rural é composto pelas empresas rurais, que realizam a produção animal ou vegetal. Em seguida, tem-se o macrossegmento industrial que pode ser dividido em: empresas de primeira, segunda e terceira transformação. De acordo com BATALHA \& SILVA (2008) as empresas de primeira transformação são as responsáveis pelos primeiros processos de transformação da matéria-prima agropecuária, estes podem ser fornecidos diretamente à comercialização ou, ainda, servir como insumos para as indústrias de segunda transformação e terceira transformação. Estas últimas que irão gerar produtos mais elaborados, como tortas, pizzas, refrigerantes, doces etc.

Para ZYLBERSZTAJN \& NEVES (2000), o SAG é visto como um conjunto de relações contratuais entre empresas e agentes que contribuem em cada elo da cadeia, cujo objetivo final é disputar o consumidor de determinado produto. Para os autores, os agentes que compõem o SAG são o consumidor, o varejo do alimento, o atacado, a agroindústria e a produção primária.

\section{COMPETITIVIDADE DAS CADEIAS PRODUTIVAS}

A competitividade está ligada à capacidade que a empresa possui. Ou ainda, como afirma SOUZA et al. (2008), deriva da produtividade da empresa e está relacionada à capacidade de o governo em criar condições favoráveis para que haja - aproveitamento dos recursos naturais e construídos, e por sua vez, pode ser medida através de indicadores nacionais quanto internacionais. Para BATALHA \& SILVA (2008), o principal indicador de competitividade está ligado à participação de uma empresa ou produto num determinado mercado, marketshare, onde se considera sua utilização ou participação neste espaço como medida de competitividade que ela possui. Ainda, segundo BATALHA \& SILVA (2008) os fatores direcionadores de competitividade estão divididos em quatro grupos sendo eles: fatores que podem ser controlados pela firma em que há estratégia, produtos, 
tecnologia, política de Recursos Humanos - $\mathrm{RH}$ e Pesquisa e Desenvolvimento P\&D; fatores controláveis pelo governo incluindo política fiscal, monetária, política educacional, leis de regulação do mercado entre outras; fatores quase controláveis como, preços de insumos, condições de demanda; e fatores não controláveis, os quais não podem ser controlados, como, fatores naturais e climáticos.

FARINA et al., (1997) conceitua competitividade através do ponto de vista das teorias da concorrência, em que está ligada a capacidade da empresa em sobreviver, crescer e se desenvolver em mercados correntes ou novos, e ainda ser sustentável na posição de realizar lucros não negativos. Já PORTER (1993) diz que a competitividade está relacionada as habilidades resultantes de conhecimentos adquiridos, e que estes são capazes de criar e sustentar um desempenho superior ao da concorrência. Pode-se dizer, que a competitividade está na capacidade de uma empresa conquistar e se desenvolver, de modo a aumentar sua participação no mercado.

Portanto, a cadeia produtiva representa as várias etapas da produção de um determinado produto, que possui elos com outros setores produtivos, como as indústrias de insumos, agricultores, indústrias de beneficiamentos, centros de distribuição e comercialização, de modo que a inter-relação entre esses agentes garantam a produção desde a fase inicial até ser entregue ao consumidor. $O$ sucesso durante várias etapas e a eficiência nos processos garantirá a competitividade da cadeia e reconhecimento tanto nacional quanto internacional (SOUZA et al., 2008; SILVA, 2013).

\section{CADEIA PRODUTIVA AVÍCOLA NO BRASIL}

O desenvolvimento da avicultura industrial mundial teve início a partir da segunda guerra, advinda da necessidade de ofertar carne aos soldados que estavam em combate. Desta forma, os EUA iniciaram o desenvolvimento de pesquisas a fim de obter novas linhagens de frangos, formulações de rações e alimentos com alto índice nutricional para as aves, além de medicamentos específicos para o setor da avicultura. Este processo continuou no pós-guerra, nos países da Europa (TAVARES \& RIBEIRO, 2007 citando BNDS, 2005; ESPINDOLA, 2012).

No Brasil, a avicultura industrial teve início na década de 50 , substituindo assim, a antiga avicultura comercial que tivera início nos anos de 1920 e 1930. Seu primeiro estágio foi marcado pela importação de linhagens hibridas americanas, que eram mais resistentes e produtivas, mais tarde através de investimentos nacionais, o setor investiu na melhoria da genética, desenvolvendo vacinas, instalações mais adequadas e alimentação mais racional. Rapidamente, a cadeia se desenvolveu dentro do país e através de características distintas, como alto grau de controle do processo biológico, possibilitou a criação do frango em condições adversas, não ficando dependentes de solo e clima, diferindo-se de outras atividades agropecuárias. O sucesso para o rápido desenvolvimento avícola no Brasil também se deve à parceria existente entre criador e indústria, que possibilitou maior estabilidade e investimento no setor (TAVARES \& RIBEIRO, 2007; BELUSSO \& HESPANHOL, 2010; MENDES, 2014).

Deste modo, a consolidação da cadeia produtiva de frango de corte ocorreu através da integração granja-indústria, ou pela chamada produção vertical, em que a agroindústria oferece os pintainhos, a ração, treinamento e orientação de melhores práticas de manejo aos produtores. Essa parceria resultou numa melhora da qualidade, e precisão na quantidade ofertada à agroindústria permitindo cálculos 
mais seguros quanto às perdas no decorrer do processo (MACHADO et al., 2014; MENDES, 2014).

Quando comparada as demais cadeias produtivas do setor agroindustrial, a cadeia produtiva de frango de corte está em destaque, tanto internamente como internacionalmente. Isso porque, o setor investe em melhorias na cadeia o que faz com que grande parte desse reconhecimento seja pela crescente utilização de tecnologias, como modernos sistemas de planejamento, organização, coordenação dos elos, técnicas gerenciais, bem como investimentos em pesquisas e estudos voltados a otimizar o setor (VOILÁ \& TRICHES, 2013).

A cadeia produtiva da avicultura é caracterizada pelos principais elos: avozeiro, matrizeiro, incubatório/nascedouro, aviário, frigorífico, varejista e consumidor final (Figura 2). Pesquisa e melhoramento genético, medicamentos, milho, soja e outros insumos, equipamentos e embalagens são caracterizados como elos auxiliares (MICHELS \& GORDIN, 2004).

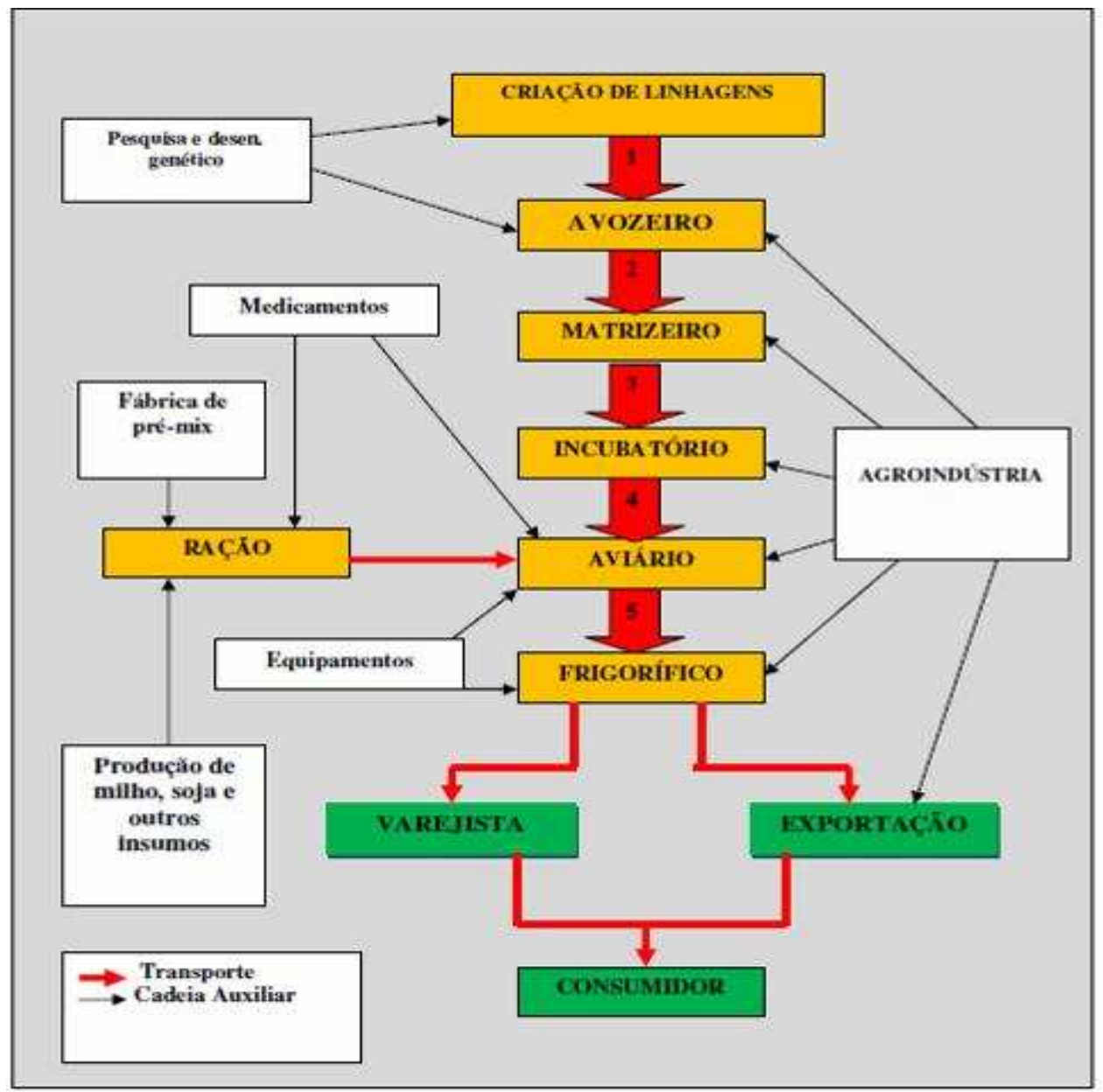

FIGURA 2: Representação da Cadeia Produtiva da Avicultura Fonte: VOILÁ \& TRICHES, 2013 adaptado de TRICHES et al. (2004).

$\mathrm{Na}$ Figura 2 tem-se a estrutura da cadeia produtiva da avicultura de corte, na qual se pode denominar cada elo da seguinte forma:

- Avozeiro: É o primeiro elo da cadeia, onde se encontram as galinhas avós, que são aquelas originárias da importação de ovos das linhagens avós. Estas são cruzadas para produzir as matrizes que vão gerar os frangos comerciais criados para o abate. 
- Matrizeiro: Geralmente pertence ao frigorífico e é nele que são produzidos os ovos férteis.

- Incubatório/nascedouro: Geralmente pertence ao frigorífico. Ali são incubados os ovos férteis e, em seguida, vão para os nascedouros, onde nascem os pintos de corte que, logo após esta etapa, são encaminhados para os aviários, que são o quarto elo da cadeia.

- Aviários: Esta etapa corresponde à produção propriamente dita, geralmente caracterizada pelos contratos de integração entre os frigoríficos e os produtores rurais. É no aviário que ocorre o processo do crescimento e engorda. Os pintinhos são levados para lá com algumas horas de nascidos e ficam até completarem 42 dias, aproximadamente, quando são transportados para o abate.

- Frigorífico: $O$ abate é feito no frigorífico, também chamado de unidade industrial, abatedouro ou empresa. É nele que se origina o produto final, o frango resfriado, congelado, inteiro e em cortes/pedaços. Esse elo é composto por vários processos que ocorrem já no local de abate são eles recepção, atordoamento, sangria, escaldagem, depenagem, evisceração, lavagem, pré resfriamento, gotejamento, pré resfriamento de miúdos, processamento de pés, classificação/cortes, embalagem, congelamento e expedição.

- Varejista: A partir do produto pronto surgem o varejista e as empresas de exportação, que irão revender o produto para os consumidores final, o último elo da cadeia, que representado tanto pelo mercado consumidor nacional quanto internacional (MICHELS \& GORDIN, 2004; ARAUJO et al., 2008).

Através dos sete principais elos da cadeia produtiva da avicultura, observa-se que em todos existem agentes externos que contribuem para o bom funcionamento da cadeia. As relações existentes entre cada etapa apresentam diferentes conotações, devido as suas funções e seu nível de poder e força que exercem na cadeia. Estas relações dependem do grau de subordinação que ocorre entre os elos (MICHELS \& GORDIN, 2004). VOILÁ \& TRICHES (2013), compreendem o processo todo da cadeia produtiva como sendo a sequência de operações, que compreende a produção de insumos, a industrialização e a comercialização e distribuição do produto final. $\mathrm{O}$ sistema engloba desde o nascimento, crescimento até a idade apropriada para o abate dos frangos e sua transformação em produto final que irá chegar até aos consumidores.

\section{MATERIAL E METODOS}

Para realização da pesquisa se procedeu com uma revisão bibliográfica, em que elaborou uma contextualização sobre a evolução da cadeia avícola no país e se identificou o desenvolvimento do setor através de investimentos em tecnologias modernas na cadeia e produção vertical, a partir de dados da União Brasileira de Avicultura - UBABEF, União Brasileira de Proteína Animal - ABPA e Departamento de Agricultura dos Estados Unidos - USDA.

A pesquisa limitou-se ao período entre os anos de 2004 a 2013, sendo os últimos dez anos da cadeia produtiva da avicultura. Verificou-se a evolução da produção, o consumo e a exportação e a competitividade do setor. Foram obtidos os valores relacionados à produção, consumo e exportação de cada ano, que posteriormente foram agrupados em tabelas para maior e melhor comparação entre os anos, após se buscou através da base de dados USDA, (2013) os principais destinos da carne produzida no país a fim de correlacioná-las com os principais 
importadores. Foram construídos gráficos que permitiram avaliar o desenvolvimento da cadeia produtiva no período.

\section{RESULTADOS E DISCUSSÕES}

A cadeia produtiva da avicultura brasileira é reconhecida internacionalmente, e segundo ARAÚJO (2008), ela pode ser considerada com uma das cadeias com um nível maior de coordenação e integração em seus elos, ganhando destaque entre as cadeias produtivas no país, e garantindo uma maior competitividade no mercado mundial. Deste modo, pode-se dizer que sua produção, a fim de atender consumidores nacionais quanto internacionais, está em constante crescimento ao longo dos dez últimos anos (Tabela 1).

TABELA 1- Produção brasileira de carne de frango no período de 2004 a 2013

\section{Ano}

$\begin{array}{llllllllll}2004 & 2005 & 2006 & 2007 & 2008 & 2009 & 2010 & 2011 & 2012 & 2013\end{array}$

\begin{tabular}{llllllllll}
\hline Quantidade 8,49 & 8,95 & 9,34 & 10,31 & 10,94 & 10,98 & 12,23 & 13,05 & 12,65 & 12,30
\end{tabular} $\left(10^{6} t\right)$

Fonte: Elaboração do autor com base nos dados dos relatórios UBABEF.

Com dados da Tabela 1 se construiu um gráfico para facilitar a visualização da oscilação na produção entre os anos do período estudado (Figura 3). Observa-se que, embora a produção esteja em constante elevação, o ponto auge da produção avícola ocorreu no ano de 2011, com 13,05 milhões de toneladas de carne de frango produzidas. Durante o ano de 2006, houve o surto da Influenza Aviária na Ásia, o que possibilitou aumentar a produção brasileira em 2007, para suprir o mercado internacional, indicando o reconhecimento da qualidade do produto brasileiro (MAPA).

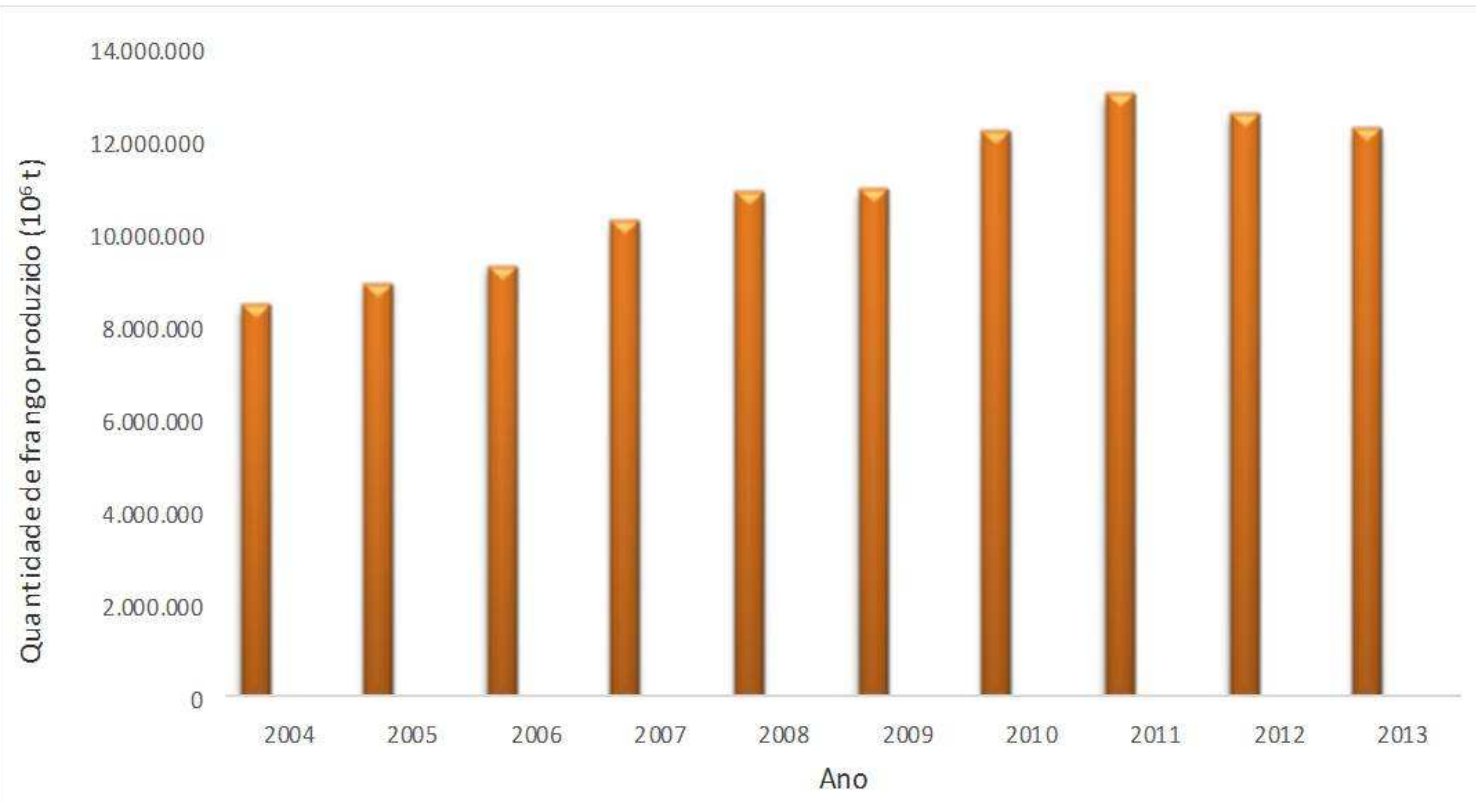

FIGURA 3 - Produção brasileira de carne de frango durante o período de 2004 a 2013. 
Fonte: Elaboração do autor com base nos dados dos relatórios UBABEF.

O parâmetro de evolução do consumo per capita no país também foi analisado (Figura 4). Observou-se que, no ano de 2004, o consumo anual de carne de frango por pessoa era de $34,89 \mathrm{~kg}$, já em 2013 este consumo aumento para $41,8 \mathrm{~kg}$ de carne de frango consumidos anualmente, ou seja, houve um aumento de pouco mais de sete quilos no decorrer do período. Assim, como na variável de produção, o consumo manteve-se em elevação ao longo dos anos, no entanto, o auge ocorreu em 2011 com o consumo de pouco mais de 47 quilos de carne de frango por pessoa.

Segundo BATALHA \& SILVA (2008), o principal indicador de competitividade de uma empresa ou produto no mercado está relacionado à sua utilização (ou consumo) de forma útil e difundida na economia. Sendo assim, o consumo é um índice da participação de mercado de um determinado produto, quanto maior sua disseminação ou consumo maior sua participação.

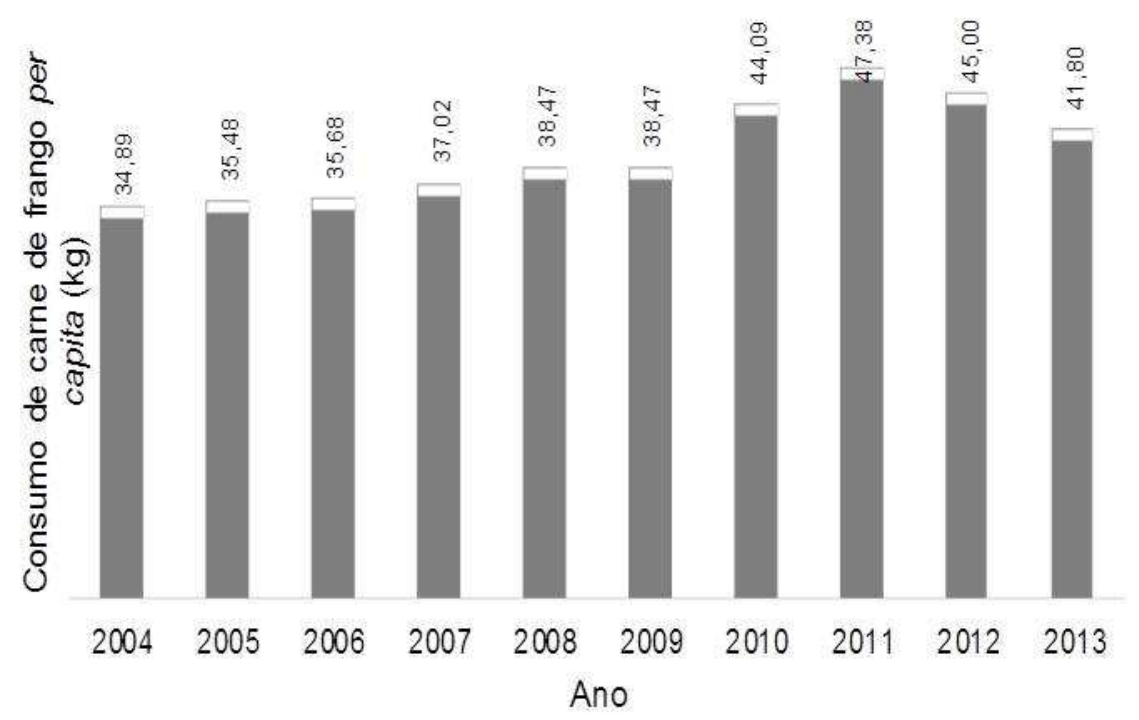

FIGURA 4 - Consumo per capita de carne de frango durante o período de 2004 a 2013.

Fonte: Elaboração do autor com base nos dados dos relatórios UBABEF.

De acordo com as análises obtidas para os dados de participação internacional da avicultura brasileira (Figura 5), observa-se que as exportações têm aumentado a cada ano ainda que com uma pequena queda entre o ano de 2012 e 2013.

Pode-se dizer que essa ascensão na exportação ao longo dos anos o que contribuiu para que país conquistasse o posto de terceiro maior produtor mundial, e sustentasse, desde o ano de 2004 a primeira posição no ranking mundial de exportação do produto (UBABEF, 2014). 


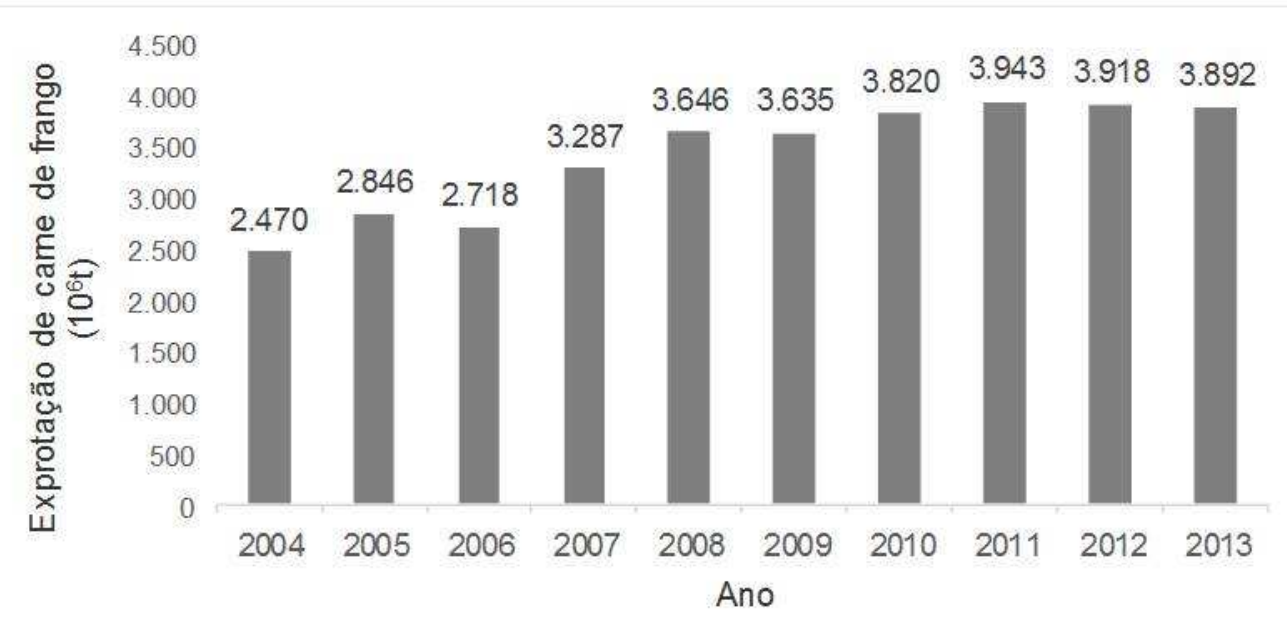

FIGURA 5 - Exportação de carne de frango durante o período de 2004 a 2013.

Fonte: Elaboração do autor com base nos dados dos relatórios UBABEF e ABPA.

As exportações brasileiras saltaram de 2.470 milhões de toneladas em 2004 para 3.918 milhões de toneladas em 2013, indicando a presença dos produtos brasileiros em constante aumento no setor internacional. Para BATALHA \& SILVA (2008), essa participação das exportações no comércio internacional torna-se um indicador de competitividade, ou seja, a capacidade de uma empresa ou indústria em oferecer produtos que atendam ou excedam a necessidade e expectativa do cliente, oferecendo mais ou além do que se é oferecido atualmente pelos seus concorrentes. Portanto, a competitividade está em conquistar o mercado oferecendo algo melhor, mais moderno e inovador do que já é ofertado por outras empresas.

Ao longo do período estudado, nota-se o aumento das importações por parte dos seis principais importadores identificados (Figura 6), em especial Japão e Arábia Saudita. Através desses dados é possível observar a consolidação do Brasil no mercado internacional, mantendo o seu índice de exportação mais elevado a cada ano.

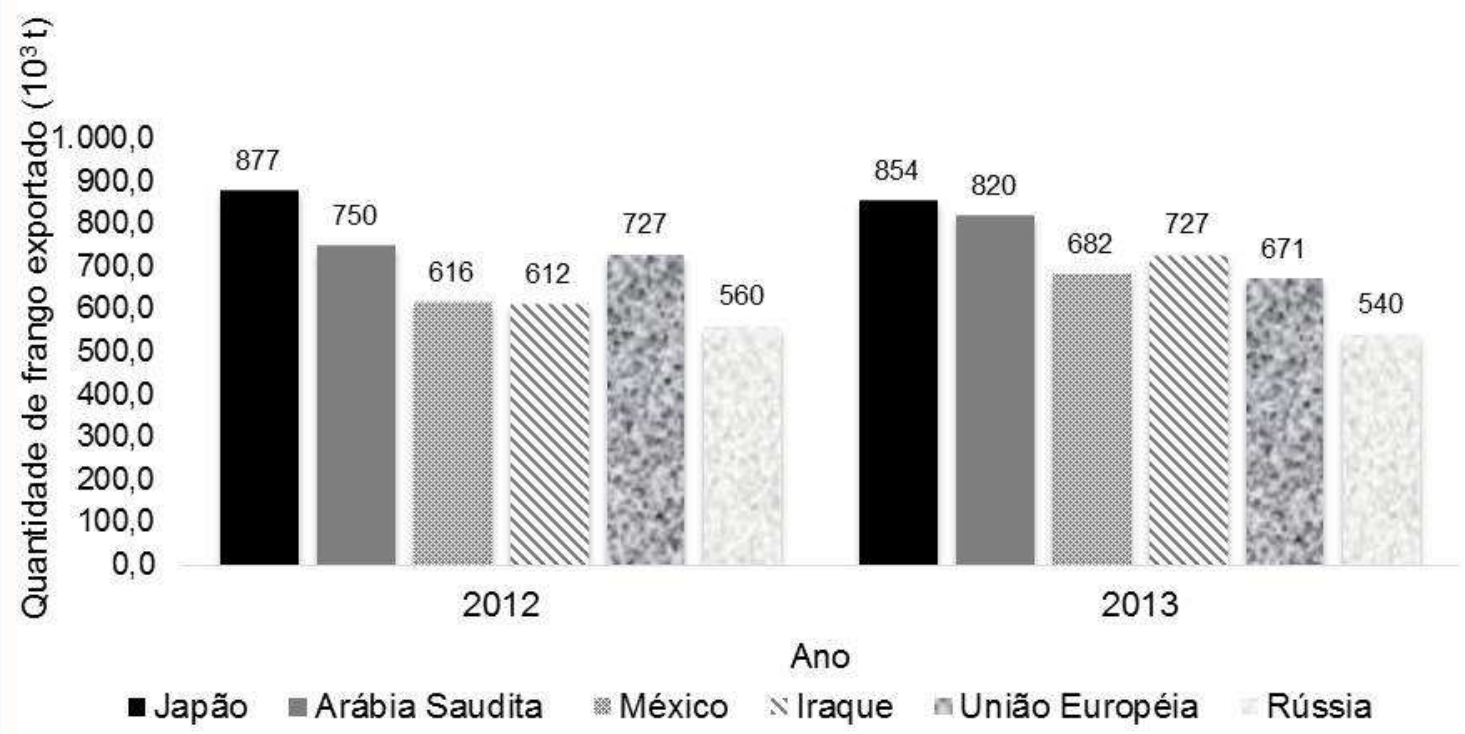

FIGURA 6 - Principais importadores mundiais de carne de frango durante o período de 2004 a 2013.

Fonte: USDA, 2013. 
A fim de justificar a competitividade da carne de frango em termos internacional, com relação a conquista de mercados, foram comparadas as exportações de carne de frango com as carnes bovina e suína. Na Figura 7, tem-se a exportação do complexo de carnes em volume no período de 1997 a 2015, sendo 2014 e 2015 uma projeção. De acordo com dados do BRADESCO \& DEPEC (2015), a carne de frango é uma das carnes mais consumidas no Brasil (Figura 7). Mundialmente, é a segunda mais consumida ficando atrás somente da carne suína. Desde 1997 o consumo de carne de frango se destaca perante outras carnes, e a projeção é que para o ano de 2015 o consumo de carne de frango seja de 3.825 milhões de toneladas, enquanto que, para a carne bovina estima-se o consumo de 2.235 milhões toneladas e para a suína 700 milhões de toneladas.

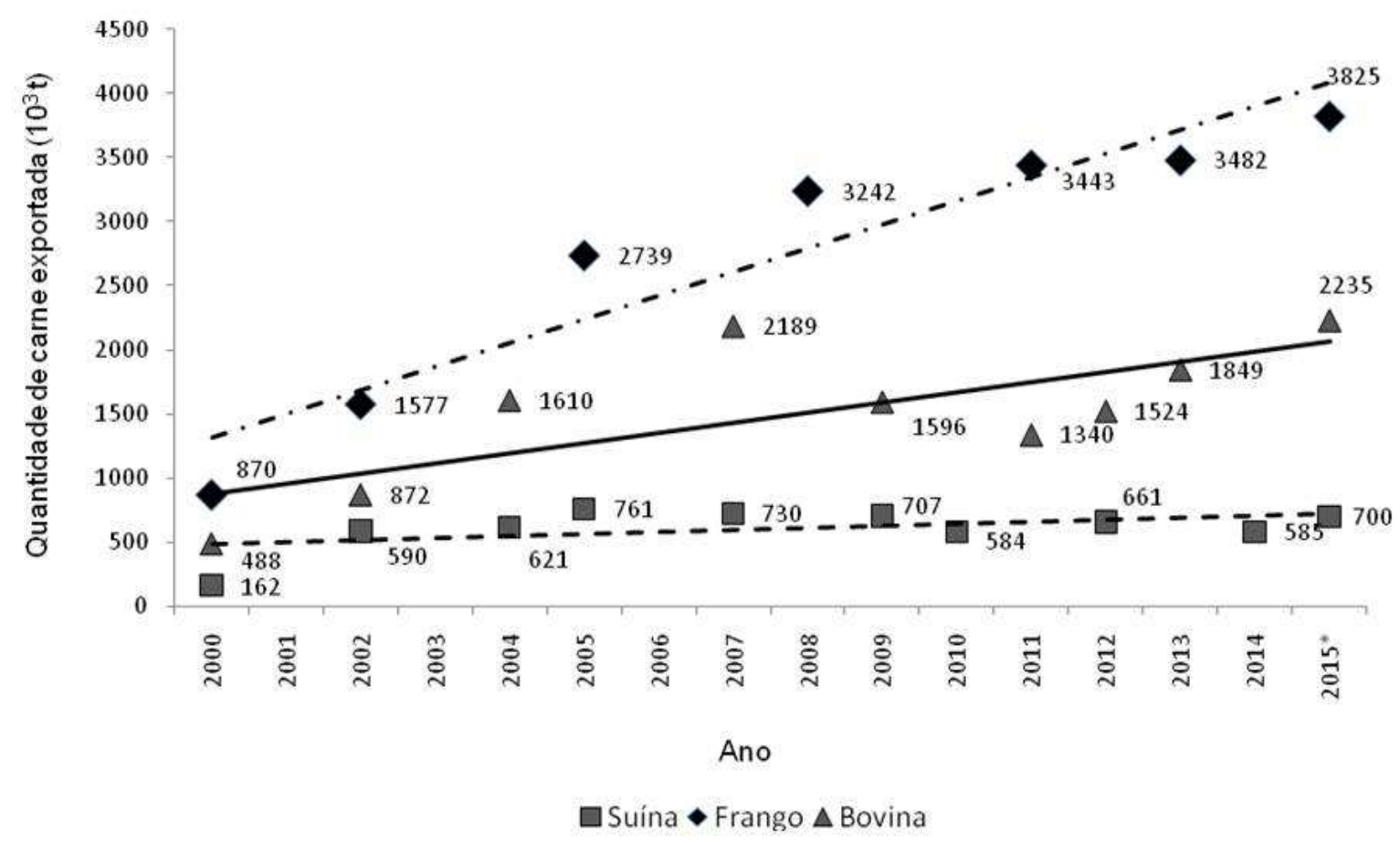

FIGURA 7 - Exportações do complexo de carnes em volume durante o período de 1997 a 2015

Fonte e projeção: USDA (2014) citado por Bradesco, 2015. (*) Projeção

De acordo com os dados analisados, pode-se afirmar que a avicultura ocupa lugar de destaque entre as cadeias mais importantes do agribusiness nacional e internacional. Segundo MENDES, 2014, este sucesso se deve à estrutura funcional brasileira (clima, água, terras cultiváveis para produção de grãos) aliado à ciência e tecnologia voltada para o desenvolvimento da avicultura, além de um mercado consumidor amplo e em constante expansão.

\section{CONCLUSÕES}

De acordo com os dados analisados durante o período de 2004 a 2013, foi possível observar a consolidação da cadeia produtiva avícola no Brasil. O país apresenta um grande potencial de produção, exportação e consumo do produto carne de frango e, desde 2004, vem evoluindo em todos os parâmetros dentro do setor. 
A carne de frango atualmente é a segunda carne mais consumida no mundo, refletindo a qualidade e modernização do processo produtivo que tem buscado a excelência nos processos, bem como a competitividade do setor, tanto nacional quanto internacional. Porém, apesar de ser o país que mais exporta carne de frango no mundo, ainda existem muitos países com grande potencial de importação do produto brasileiro que ainda não foram conquistados e, para que isso ocorra, é preciso investir em qualidade e divulgação do produto.

\section{REFERÊNCIAS}

ASSOCIAÇÃO BRASILEIRA DE PROTEINA ANIMAL - ABPA. Disponível em: <www.abpa-br.or> Acesso em: 02 de maio de 2015.

\section{ASSOCIAÇÃO BRASILEIRA DE PROTEINA ANIMAL - ABPA. Cenário Carnes} 2014/2015.

em:

<http://www.agricultura.gov.br/arq_editor/file/camaras_setoriais/Aves_e_suinos/25R

O/Cen\%C3\%A1rio\%20Carnes\%202014\%202015.pdf> Acesso em: 20 de setembro de 2009.

ARAUJO, G. C.; BUENO, M. P.; BUENO, V. P.; SPROESSER, R. L.; SOUZA, I. F. Cadeia Produtiva da Avicultura de Corte: Avaliação da Apropriação de Valor Bruto nas transações Econômicas dos Envolvidos - 2008. Disponível em: <seer.uscs.edu.br/index.php/revista_gestao/article/viewFile/95/58> Acesso em: 20 de maio de 2015.

BANCO NACIONAL DE DESENVOLVIMENTO ECONÔMICO E SOCIAL - BNDES. Relato setorial avicultura. Rio de Janeiro, 2005. Disponível em: <http://www.bndes.gov.br>. Acesso em: 22 de maio de 2015.

BATALHA, M. O. As cadeias de produção agroindustriais: uma perspectiva para o estudo das inovações tecnológicas. Revista de Administração, São Paulo, v. 29, n. 4, p. 43-50, 1995.

BATALHA, M. O.; SILVA, A. L. Gestão Agroindustrial: GEPAI: Grupo de estudos e pesquisas agroindustriais. In: BATALHA, M. O. (Coord). 3. ed. - 2. reimpr. - São Paulo: Atlasp., p. 1-62, 2008.

BELUSSO, D.; HESPANHOL, A. N. A Evolução da Avicultura Industrial Brasileira e seus Efeitos Territoriais. Revista Percurso - NEMO. Maringá, v.2, n.1, p. 25-51, 2010.

BRADESCO; DEPEC- Departamento de Pesquisas e Estudos Econômicos Relatório de Consumo de Carnes. Março de 2015. Disponível em: $<$ www.economiaemdia.com.br/EconomiaEmDia/pdf/infset_carne_avicola.pdf> Acesso em: 05 de maio de 2015.

CASTRO, A. M. G. Prospecção de cadeias produtivas e gestão da informação. Transinformação, v.13, n. 2, p. 55-72, 2001.

DAVIS, J.; GOLDBERG, R. A concept of agribusiness. Boston: Harvard University. 1957. $135 \mathrm{p}$. 
ESPÍNDOLA, C.J. Trajetórias do progresso técnico na cadeia produtiva de carne de frango do Brasil. Revista Geosul, v. 27, n. 53, p. 89-113, 2012.

FARINA, E. M. M. Q.; AZEVEDO, P. F.; SAES, M. S. M. Competitividade: mercado, estado e organização. São Paulo: 1 ed. Editora Singular, 1997. 286p.

MACHADO, S. T. REIS, J. G. M. VENDRAMETTO, O. Nääs, I. A. Logística Aplicada Á Produção De Aves De Corte: Desafios No Manejo Pré Abate. Enciclopédia Biosfera , Centro Científico Conhecer - Goiânia, v.10, n.18; p. 2108. 2014.

MENDES, A. A. A Cadeia Avícola Brasileira. In. Livro: Produção de Frangos de Corte / Marcos Macari [et al.]. - Campinas: FACTA, 2014. 565p.

MICHELS, I. (Coord.); GORDIN, M. H. Avicultura. Campo Grande: UFMS, 2004, 158 p. (Cadeias produtivas de Mato Grosso do Sul, v. 1).

MINISTÉRIO DA AGRICULTURA, PECUÁRIA E ABASTECIMENTO - MAPA. Influenza Aviária. Informe-se. Secretária de Defesa Agropecuária. Departamento de Saúde Animal. Coordenação-Geral de Combate ás Doenças. Coordenação de Sanidade Avícola. Disponível em: < http://www.agricultura.gov.br/arq_editor/file/Aniamal/programa\%20nacional\%20sanid ade\%20avicola/perguntas\%20frequentes.pdf>. Acesso em: junho de 2015.

PIZZOLATTI, I. J. Visão e Conceito de Agribusiness (2004). Disponível em: <http://biblioteca.sebrae.com.br/bte/bte.nsf/C84FADCED2D0109E03256F0E00788F A6/\$File/NT0009853A.pdf>. Acesso em: 02 jun. 2015.

PORTER, M. E. A vantagem competitiva das nações. 5 ed. Rio de Janeiro, RJ: Campus, 1993. $897 \mathrm{p}$.

SILVA, T. M. Caracterização da Estrutura da Cadeia Produtiva da Olivicultura no Estado do Rio Grande do Sul: 0 caso das Propriedades Rurais de Cachoeira do Sul. 2013. Trabalho de conclusão de curso de Graduação Tecnológica em Desenvolvimento Rural - PLAGEDER, Faculdade de Ciências Econômicas da Universidade Federal do Rio Grande do Sul - UFRGS. Disponível em: <www.lume.ufrgs.br/handle/10183/87431 ?locale=pt_BR > Acesso em: 23 de abril de 2015.

SOUZA, L. G. A.; CAMARA, M. R. G.; SEREIA, V. J. Exportações e competitividade da carne de frango brasileira e paranaense no período de 1990 a 2005. Revista Semina: Ciências Sociais e Humanas, Londrina, v. 29, n. 1, p. 101-118, 2008.

SOUZA, J. P; AVELHAN, B. L. Aspectos Conceituais Relacionados A Análise De Sistemas Agroindustriais. Caderno de Administração. Universidade Estadual de Maringá - Centro de Ciências Sociais Aplicada - Departamento de Administração, v. 17, n.2, 2009.

TALAMINI, D. D.; MARTINS, F. M.; OLIVEIRA, A. J. Custos da Cadeia Produtiva do Frango: Parceria entre Cooperativa e Pequenos Produtores Familiares no 
Estado de Santa Catarina. Santa Catarina, SC., 2013. Disponível em: $<w w w . s o b e r . o r g . b r / p a l e s t r a / 5 / 1064$.pdf> Acesso em: 29 de abril de 2015.

TAVARES. L. P.; RIBEIRO. K. C. S. Desenvolvimento da Avicultura de Corte Brasileira e perspectivas frente a influenza aviária. Organizações Rurais e Agroindustriais, Lavras-MG, v. 9, n. 1, p. 79-88, 2007.

TRICHES, D. ; CALDART, W. L. ; SIMAN, R. F. ; STÜLP, V. J. A cadeia produtiva da carne de frango da região da serra gaúcha: Uma análise da estrutura de produção e mercado. In: Congresso da Sociedade Brasileira de Economia e Sociologia Rural, XLIII, Ribeirão Preto, USP. Ribeirão Preto: v. 1, 24 a 15 de Set. 2004.

União Brasileira De Avicultura- UBABEF. Relatórios Anuais, 2004 á 2013. Disponível em: <www.ubabef.com.br>. Acesso em 12 abril de 2015.

UNITED STATES DEPARTMENT OF AGRICULTURE - USDA. Disponível em: <www.usda.gov/wps/portal/usda>. Acesso em: 03 de junho de 2015.

VOILÁ, M.; TRICHES, D. A Cadeia de Carne de Frango: Uma Análise dos Mercados Brasileiro e Mundial de 2002 a 2010. IPES Texto para Discussão. Publicação do Instituto de Pesquisas Econômica e Sociais. Universidade de Caxias do Sul. Janeiro, 2013.

ZANELLA, C.; LEITE, A. L. S.; FIATES, G. G. S.; CARIO, S. A. F. A Verticalização da Cadeia Produtiva de Frango da Região de Chapecó - SC. Revista Alcance Eletrônica v. 20, n. 4, p. 533-550, 2013.

ZILBERSTAJN, D.; NEVES, M. F.; Economia e gestão dos negócios agroalimentares: Indústria de alimentos, indústria de insumos, produção agropecuária, distribuição l. 1 ed. São Paulo: Pioneira Thomson, 2000. 428 p. 